\title{
Delineation of Management Zones Using Soil Properties and a Multivariate Geostatistical Approach
}

\author{
Gabriele Buttafuoco*1, Annamaria Castrignanò ${ }^{2}$, \\ Antonio Salvatore Colecchia ${ }^{3}$, Nicola Ricca ${ }^{1}$ \\ ${ }^{1}$ CNR - Istituto per i Sistemi Agricoli e Forestali del Mediterraneo (ISAFOM) \\ Via Cavour 4-6, 87036 Rende (CS), Italy \\ ${ }^{2}$ CRA - Unità di Ricerca per i Sistemi Colturali degli Ambienti Caldo-Aridi \\ Via C. Ulpiani 5, 70125 Bari, Italy \\ ${ }^{3}$ Dipartimento di Scienze degli Alimenti, Università di Teramo \\ Via Lerici 1, 64023 Mosciano Sant'Angelo (TE), Italy
}

Received: 9 September 2009. Accepted: 15 May 2010.

\begin{abstract}
Agricultural fields naturally have within-field variations that may cause spatial variability in crop yields. Delineating a field into a few management zones (MZ) is therefore a practical management approach for precision agriculture. In this study, some soil properties (clay content, organic matter content and water content measured at different dates) and a multivariate geostatistical approach were used to delineate management zones. The temporal stability of soil water content spatial patterns may be an additional approach in delineating management zones.

The present study was conducted on a $120000 \mathrm{~m}^{2}$ durum wheat field in Southern Italy, where soil properties and soil water content were measured at different times over three crop seasons (2005-06, 2006-07, and 2007-08) at 100 locations.

The multivariate spatial and temporal data were analysed by Factor Kriging Analysis (FKA). All simple and cross model variograms were calculated by fitting a linear model of coregionalization including the nugget effect and two spatial structures at shorter $(70 \mathrm{~m})$ and longer range $(500 \mathrm{~m})$. The application of factor kriging allowed us to identify one regionalized factor at longer scale and to partition the field from the point of view of temporal stability of soil water content, into contiguous zones to be submitted to site-specific management. The method showed a great flexibility to combine data from several sources in the delineation of management zones.
\end{abstract}

Key-words: factor kriging, management zones, multivariate geostatistics, precision agriculture.

\section{Introduction}

Precision agriculture (site-specific crop management) is aimed at managing soil spatial variability to supply actual requirements of a specific soil and crop to parts of fields rather than average needs to whole fields (Doerge, 1999; Mzuku et al., 2005). Site-specific crop management requires to delineate management zones (MZ) which are defined as homogeneous subfield regions that have similar yield limiting factors or similar attributes affecting yield (e.g. topography, soil nutrient test levels) (Doerge, 1999; Khosla and Shaver, 2001; Fridgen et al., 2004; Basso et al., 2007). Determination of these sub-field areas is difficult due to the interactions among several biotic, abiotic and climate factors that affect crop yield. Different approaches have been developed for site-specific management zone delineation: topography and soil properties, including soil survey maps (Carr et al., 1991) and soil sampling (Mulla, 1991); landscape factors obtained from digital elevation models (DEM) (McCann et al., 1996; Lark, 1998; Nolan et al., 2000), aerial photographs of bare soil (Fleming et al., 2000), remote sensing images (Bhatti et al., 1991; Moulin et al., 1998), invasive soil sampling (Mulla, 1991) and non-invasive soil sampling using electrical conductivity 
(Johnson et al., 2003; Castrignanò et al., 2006). Therefore, combining several types of data (soil, landscape, crop, yield and multiple remote sensing images) is supposed to partly compensate the weakness of the approaches using a single source of information and, above all, to produce more stable management zones.

It is well known that soil water in a field varies over time and location (Starr, 2005; Guber et al., 2008) and that when a field is repeatedly surveyed for soil water content, locations can identified where soil water contents are either consistently larger or consistently less than the study area average (Vachaud et al., 1985; Kachanoski and De Jong, 1988; Jaynes and Hunsaker, 1989; Zhai et al., 1990; Goovaerts and Chiang, 1993; Comegna and Basile, 1994; Tomer and Anderson, 1995; Pires da Silva et al., 2001; Guber et al., 2008). This phenomenon has been called temporal stability (Vachaud et al., 1985), temporal persistence (Kachanoski and de Jong, 1988), or rank stability (Tallon and $\mathrm{Si}, 2003$ ) in soil water content spatial patterns. The stable pattern of spatial variability has been correlated with relatively stable properties as topography and soil particle class (Starr, 2005). Vachaud et al. (1985) pointed out to the role of soil particle size in explaining soil water temporal stability.

The temporal stability of soil water content spatial patterns may be an additional approach in delineating management zones that has received little attention in literature (Starr, 2005).

Geostatistical methods (Matheron, 1970) can treat soil properties (i.e., water content, particle size, organic matter content) as continua in a joint attribute and geographical space. Each attribute is considered as a random regionalized variable, varying continuously, whose spatial variation is described by a covariance function. In particular a multivariate geostatistical approach, based on Principal Component Analysis (PCA) and called factor kriging (Matheron, 1982), uses the information coming from both relationships among variables and spatial dependence between observations to subdivide an agricultural field into more homogeneous units, with respect to soil physical, chemical and hydraulic properties (Castrignanò et al., 2000). Moreover, some factors that affect crop response are likely to have a short-range action, whereas others operate at longer distances, therefore delineation of potential management zones is expected to be scale-dependent.

The main objective of this paper was to propose a method for delineating potential management zones based on some soil properties (clay content, organic matter content and water content measured at different dates) and a multivariate geostatistical approach. The proposed method produces a continuous scale-dependent classification of the field by combining classical PCA with geostatistics.

\section{Materials and methods}

\section{Study site}

The study was carried out in the experimental farm of the CRA-Experimental Center for the Cereals, located near Foggia $\left(41^{\circ} 27^{\prime} \mathrm{N}, 15^{\circ} 36^{\prime}\right.$ E, $90 \mathrm{~m}$ above sea level), south-eastern Italy. A field trial on rainfed durum wheat (Figure 1) was carried out on a $120000-\mathrm{m}^{2}$ field cropped to durum wheat (Triticum durum Desf.). The soil is a deep, silty-clay Vertisol of alluvial origin, classified as fine, mesic, Typic, Chromoxerert (Soil Survey Staff, 1999). The climate is Mediterranean, characterised by hot and dry summers and rainfall concentrated mostly in the winter months.

\section{Sampling scheme and data}

One hundred georeferenced locations (Fig. 1) were selected so that they evenly covered the field by using a modified version of spatial simulated annealing (Castrignanò et al., 2008). The total number of samples was dictated by financial constraints and considerations on estimation precision: a rate of approximately 10 samples per $10000 \mathrm{~m}^{2}$ was deemed as a good tradeoff. The soil samples were collected at the 100 georeferenced locations within the field and sand, silt, clay, organic matter contents (\%) were determined. Sand, silt and clay contents were determined by the pipette method (Pagliai, 1997), while organic matter content by Walkley Black method (Violante, 2000). In this study we used only clay and organic matter contents.

In the same 100 points, volumetric soil water contents were measured at nine dates in three crop seasons (2005-2006, 2006-2007, 20072008) with a Time Domain Reflectometer, TDR (TRASE Systems, Soilmoisture Equipment 


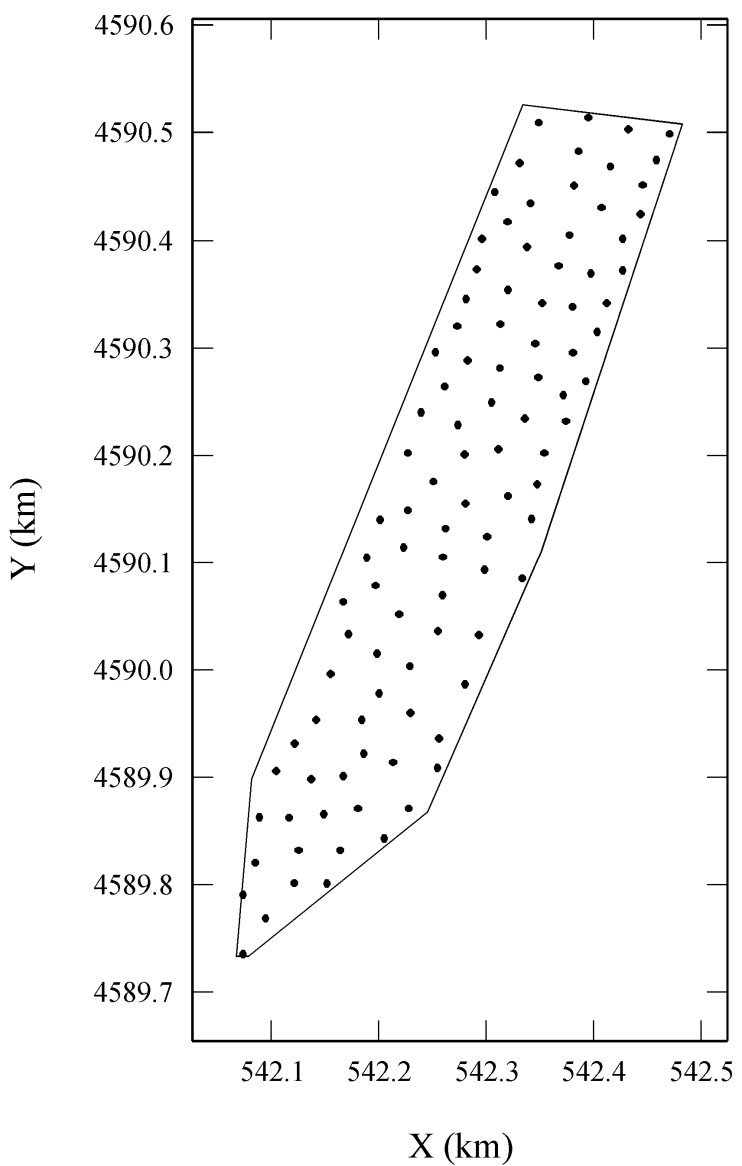

Figure 1. Sampling locations.

Corp., Santa Barbara, CA). Detailed descriptions of TDR principle, technique and design can be found in Topp et al. (1980), Topp and Davis (1985), Dalton and van Genuchten (1986), Zegelin et al. (1992), Cassel et al. (1994). The probe consisted of two parallel 6-mm thick and $0.15-\mathrm{m}$ long stainless steel rods.

From soil water content data the standardized relative difference $\left(\delta_{i j}\right)$ was computed according to Vachaud et al. (1985) equation:

$$
\delta_{i j}=\frac{\Delta_{i j}}{w_{a v g}}
$$

where $\Delta_{i j}$ is the difference between the water content at location $i(i=1, \ldots, 100)$ and the field average water content $w_{\text {avg }}$ at sampling date $j(j$ $=1, \ldots, 9)$. Negative values of $\delta_{i j}$ correspond to the drier spots, while the positive ones to the wetter spots. The values of $\delta_{i j}$ equal or very close to zero represent those zones whose water con- tents did not vary greatly over time, conserving a value close to the field average at the sampling date.

\section{Geostatistical methods}

In Geostatistics each measured value at a set of locations is interpreted as a particular realization or outcome of a random variable. For a detailed presentation of the theory of geostatistics, interested readers should refer to texts such as Chilès and Delfiner (1999), Wackernagel (2003), Webster and Oliver (2007), among others.

Multi-Gaussian approach. Even if ordinary cokriging does not require the data to follow a normal distribution, variogram modelling is sensitive to strong departures from normality, because a few exceptionally large values may contribute to many very large squared differences. In this scope, to produce the map of the variables we used multi-Gaussian cokriging. It is based on a multi-Gaussian model and requires a prior Gaussian transformation of the initial attribute into a Gaussian-shaped variable with zero mean and unit variance. Such a procedure is known as Gaussian anamorphosis (Chilès and Delfiner, 1999; Wackernagel, 2003) and it is a mathematical function which transforms a variable with a Gaussian distribution into a new variable with any distribution. The Gaussian anamorphosis can be achieved using an expansion into Hermite polynomials $H_{i}(Y)$ (Wackernagel, 2003) restricted to a finite number of terms.

Multivariate geostatistical approach. The multivariate spatial data were analysed by cokriging and Factor Kriging Analysis (FKA,) which is a geostatistical method developed by Matheron (1982). The theory underlying FKA has been described in many papers (Goovaerts, 1992; Goovaerts and Webster, 1994; Castrignanò et al., 2000; Wackernagel, 2003; Webster and Oliver, 2007). The approach consists of decomposing the set of original second-order random stationary variables $\left\{Z_{i}\left(\mathbf{x}_{\alpha}\right), i=1, \ldots, p ; \alpha=1, \ldots, n\right\}$ into a set of reciprocally orthogonal regionalized factors $\left\{Y_{v}^{u}(\mathbf{x}), v=1, \ldots, p ; u=1, \ldots, N_{s}\right\}$ where $N_{S}$ is the number of spatial scales, through transformation coefficients $a_{i v}^{u}$ (loadings components score) combining the spatial with the multivariate decomposition: 


$$
Z_{i}\left(\mathrm{x}_{\alpha}\right)=\sum_{u=1}^{N_{S}} \sum_{v=1}^{p} a_{i v}^{u} Y_{v}^{u}(\mathrm{x})
$$

The three basic steps of FKA are the following:

1) modelling the coregionalization of the set of variables, using the so called Linear Model of Coregionalization (LMC);

2) analysing the correlation structure between the variables, by applying Principal Component Analysis (PCA) at each spatial scale;

3) cokriging specific factors at each characteristic scale and mapping them.

Linear Model of Coregionalization (LMC). The LMC, developed by Journel and Huijbregts (1978), considers all the studied variables as the result of the same independent physical processes, acting at different spatial scales. The $p(p+1) / 2$ simple and cross variograms of the $p$ variables are modelled by a linear combination of $N_{S}$ standardized variograms to unit sill $g^{u}(\mathbf{h})$. Using the matrix notation, the LMC can be written as:

$$
\tilde{\mathbf{A}}(\mathbf{h})=\sum_{u=1}^{N_{S}} \mathbf{B}^{u} g^{u}(\mathbf{h})
$$

where $\tilde{\mathbf{A}}(\mathbf{h})=\left[\gamma_{i j}(\mathbf{h})\right]$ is a symmetric matrix of order $p \times p$, whose diagonal and non diagonal elements represent simple and cross variograms for lag $\mathbf{h} ; \mathbf{B}^{u}=\left[b_{i j}^{u}\right]$ is called coregionalization matrix and it is a symmetric semi-definite matrix of order $n \times n$ with real elements $b_{i j}^{u}$ at a specific spatial scale $u$. The model is authorized if the functions $g^{u}(\mathbf{h})$ are authorized variogram models. In the LMC the spatial behaviour of the variable is supposed resulting from superimposition of different independent processes working at different spatial scales. These processes may affect the behaviour of experimental semivariograms, which can be modelled by a set of functions $g^{u}(\mathbf{h})$. Fitting of LMC is performed by weighed least-squares approximation under the constraint of positive semi-definiteness of the $\mathbf{B}^{u}$, using the iterative procedures developed by Goulard and Voltz (1992). The best model was chosen, as suggested by Goulard and Voltz (1992).

The goodness of estimation approach is evaluated with a cross-validation test by calculating: 1) mean error, which proves the unbiasedness of estimate if its value is close to 0 , and 2) the variance of the standardized error by kriging standard deviation. If the model for the variogram is accurate, the mean squared error should equal the kriging variance and then the variance of the standardized error should be close to 1 .

The transformed data are estimated at all unsampled locations using ordinary cokriging. Finally, the estimates are back transformed to the raw data through the mathematical model calculated in Gaussian Anamorphosis.

Regionalized Principal components Analysis. Regionalized principal component analysis consists in decomposing each coregionalization matrix into eigenvalues and eigenvectors matrices (Wackernagel, 2003).

The transformation coefficients $a_{i v}^{u}$ correspond to the covariances between the original variables and the principal component, called regionalized factors, at a given spatial scale.

Cokriging and mapping of Regionalized Factors. Regionalized principal component analysis consists in decomposing each coregionalization matrix $\mathrm{B}^{u}$ into eigenvalues and eigenvectors matrices (Wackernagel, 2003):

$$
\mathbf{B}^{u}=\mathbf{Q}^{u} \ddot{\mathbf{E}}^{u} \mathbf{Q}^{u T}=\left(\mathbf{Q}^{u} \sqrt{\ddot{\mathbf{E}}^{u}}\right)\left(\mathbf{Q}^{u} \sqrt{\ddot{\mathbf{E}}^{u}}\right)^{T}=\mathbf{A}^{u} \mathbf{A}^{u T}
$$

where $\mathrm{Q}^{u}$ is the matrix of eigenvectors and $\ddot{\mathrm{E}}^{u}$ is the diagonal matrix of eigenvalues for each spatial scale $u ; \mathbf{A}^{u}=\mathbf{Q}^{u} \sqrt{\ddot{\mathbf{E}}^{u}}$ is the matrix of order $n \times n$ of the transformation coefficients $a_{i v}^{u}$. The transformation coefficients $a_{i v}^{u}$ in the matrix $\mathrm{A}^{u}$ correspond to the covariances between the original variables $Z_{i}(\mathrm{x})$ and the regionalized factors $Y_{v}^{u}(\mathrm{x})$. The behaviour and relationships among variables at different spatial scales can be illustrated by mapping the regionalized factors estimated by cokriging (Castrignanò et al., 2000). The cokriging systems have been widely described by Wackernagel (2003).

All statistical and geostatistical analyses were done by using the software package ISATIS $®$, release 9.0 (Geovariances, 2009).

\section{Results and discussion}

Basic statistics of clay, organic matter (OM), and soil water content for each date of measurement are reported in Table 1. Soil clay content varied from 8.50 to $50.03 \%$ and its distribution was 
Ital. J. Agron. / Riv. Agron., 2010, 4:323-332

Table 1. Basic statistics of clay (\%), organic matter (\%), and soil water content, $\theta,\left(\mathrm{m}^{3} \mathrm{~m}^{-3}\right)$ for each date of measurement.

\begin{tabular}{|c|c|c|c|c|c|c|c|}
\hline & Minimum & Mean & Maximum & Standard Deviation & $\mathrm{CV}$ & Skewness & Kurtosis \\
\hline Clay & 8.50 & 27.53 & 50.03 & 7.44 & 0.27 & 0.22 & 3.19 \\
\hline $\mathrm{OM}$ & 1.51 & 1.88 & 2.30 & 0.14 & 0.08 & 0.19 & 3.26 \\
\hline$\theta-170206$ & 0.277 & 0.431 & 0.548 & 0.053 & 0.12 & -0.67 & 3.13 \\
\hline$\theta-090506$ & 0.146 & 0.215 & 0.306 & 0.039 & 0.18 & 0.40 & 2.59 \\
\hline$\theta-300506$ & 0.112 & 0.147 & 0.191 & 0.014 & 0.10 & 0.09 & 3.06 \\
\hline$\theta-120207$ & 0.144 & 0.262 & 0.369 & 0.041 & 0.16 & 0.43 & 3.56 \\
\hline$\theta-060407$ & 0.025 & 0.118 & 0.250 & 0.052 & 0.45 & 0.45 & 2.45 \\
\hline$\theta-140507$ & 0.093 & 0.156 & 0.261 & 0.027 & 0.18 & 0.48 & 4.58 \\
\hline$\theta-100408$ & 0.197 & 0.333 & 0.548 & 0.048 & 0.14 & 0.96 & 7.80 \\
\hline$\theta-240408$ & 0.155 & 0.244 & 0.324 & 0.042 & 0.17 & -0.18 & 1.92 \\
\hline$\theta-090508$ & 0.048 & 0.170 & 0.275 & 0.046 & 0.27 & -0.38 & 3.07 \\
\hline
\end{tabular}

symmetrical and the $\chi^{2}$ test showed that the hypothesis of normality cannot be refused at a probability level greater than 0.05 (experimental $\chi^{2}=14.35$ ). The OM content varied from 1.51 to $2.30 \%$ and the results of the $\chi^{2}$ test showed that the hypothesis of normality cannot be accepted at a probability level greater than 0.10 (experimental $\chi^{2}=29.40$ ).

The soil water content mean values were greatly affected by the rainfall pattern decreasing from February to May. Only in 2007 the mean soil water content value in May was higher than the one in April as consequence of precipitation occurred in May 2007. Soil water content distributions were generally symmetric and except 3 measurement dates (17-02-2006, 14-052007, and 24-04-2008), the $\chi^{2}$ test showed that the hypothesis of normality cannot be refused at a probability level greater than 0.05 .

From the soil water content data, the standardized relative differences, $\delta_{i j}$, corresponding to the nine sampling dates were computed using Eq. (1). Due to the diversity of measurement units and because multi-Gaussian approach requires a multi-Gaussian framework, all the variables were normalized and standardized to mean 0 and variance 1 , by using Hermite polynomial expansions restricted to the first 30 elements.

The variographic analysis allowed to compute the experimental simple and cross-variograms of clay, organic matter contents, and the standardized relative differences. No relevant anisotropy was observed in the variogram maps (not shown) and the experimental variograms looked upper bounded. Therefore, an isotropic LMC was fitted to experimental simple and cross-variograms including three basic spatial structures: (1) a nugget effect; (2) a spherical model (Webster and Oliver, 2007) with range of $70 \mathrm{~m}$ and (3) a spherical model with range of $500 \mathrm{~m}$. Figure 2 shows some of auto- and crossvariograms of the Gaussian variables of Clay and OM content, and the Gaussian differences mean standardized. Most of variation was erratic and not spatially correlated. Indeed, the nugget component was also large; this comprises mainly variation at scales smaller than $35 \mathrm{~m}$ (the average sampling interval) and to a lesser extent measurement error. To resolve some of the nugget component of the variation, further sampling on a finer spatial scale would be needed.

The appropriateness of the LMC was evaluated with a cross-validation test by calculating mean error and the variance of standardized error, which were quite close to 0 (varying between -0.026 and 0.028 ) and 1 (varying between 0.90 and 1.22 ), respectively.

The spatial maps of the eleven variables were obtained by cokriging on a $1 \mathrm{~m} \times 1 \mathrm{~m}$ square grid. Figure 3 show the maps of clay, OM content, and the mean of the standardized relative differences. From an inspection of the map, it is possible identify the wettest zones (positive values) in the southern part of the field and in a little spot in the northern part. The driest zones (negative values) are located in the centrenorthern part of the field. There are two large zones extending across the centre-northern and centre-southern parts of the field, where the water contents generally matched the average value of the field (values equal or very close to zero). The driest zones correspond to presence of coarse sand (map not shown) and from the map of the coefficient of variation of the spatial-temporal soil water content, it can identify the dri- 

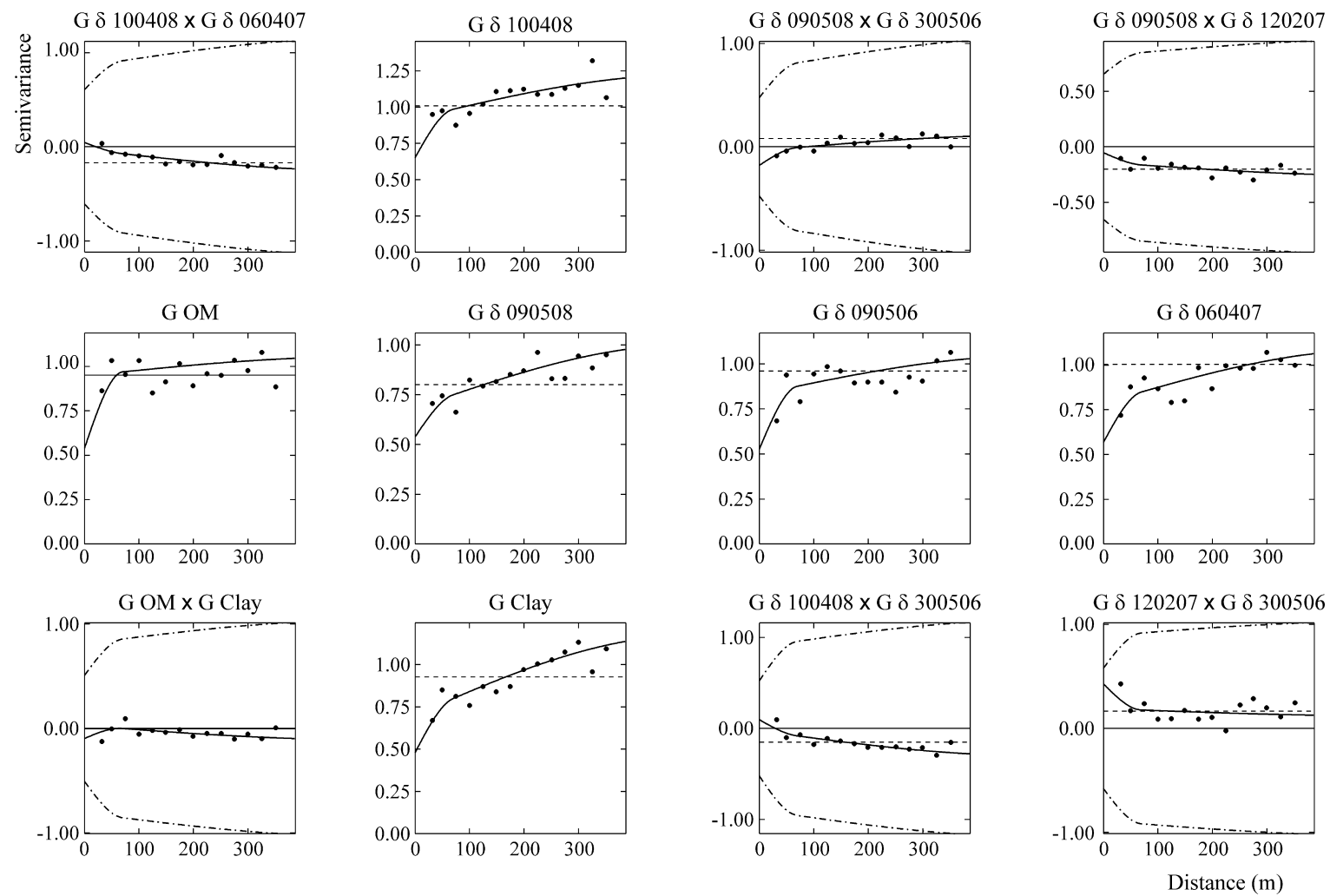

Figure 2. Some auto- and cross-variograms of the Gaussian variables of Clay and OM content, and the Gaussian differences mean standardized. The experimental values are the plotted points and the solid lines are of the model of coregionalization. The dash-dotted lines are the hull of perfect correlation and the dashed lines are the experimental variances.

est zones with the higher values of $\mathrm{CV}$ of soil water content. The wettest zones correspond to the smaller values of $\mathrm{CV}$. With a few exceptions, the smaller values of OM content correspond in a way to the driest zones.

To aggregate and summarize the joint variability in the clay, OM, and relative differences $\left(\delta_{i j}\right)$, standardized PCA was performed at the basic spatial scales. A summary of the results obtained is presented in Table 2. The loadings (coefficients of transformation of Eq. 2) for each variable in relation to the principal components (regionalized factors) are given as well as the eigenvalues and the percentage of explained variance for each of the components. The sum of the eigenvalues at each spatial scale gives an estimate of the variance at that scale (Tab. 2). The nugget was about $53 \%$ of total variance (12.07), while the contribution of the shorter range component $(70 \mathrm{~m})$ of variation to the total variance was $25 \%$ and the contribu- tion of the longer range component $(500 \mathrm{~m})$ was $22 \%$. Moreover, the matrix of eigenvectors (regionalized factors) contains the information if some meaning can be attached to the principal components. The elements of an eigenvector represent the contribution of the original variate to that component. An element of an eigenvector with a value near 1 means that the original variate makes a large contribution to that component. Conversely, if an element of an eigenvector is near 0 the contribution to that component is small. Therefore, by examining the eigenvectors it may be possible to give the principal components a physical interpretation. However, the principal components (PCs) are no more than mathematical constructs, and they have no direct physical meaning. Therefore, an interpretation is by no means assured. In this scope, we retained the PCs (regionalized factors) producing eigenvalues greater than one and omitted the ones corresponding to nugget 

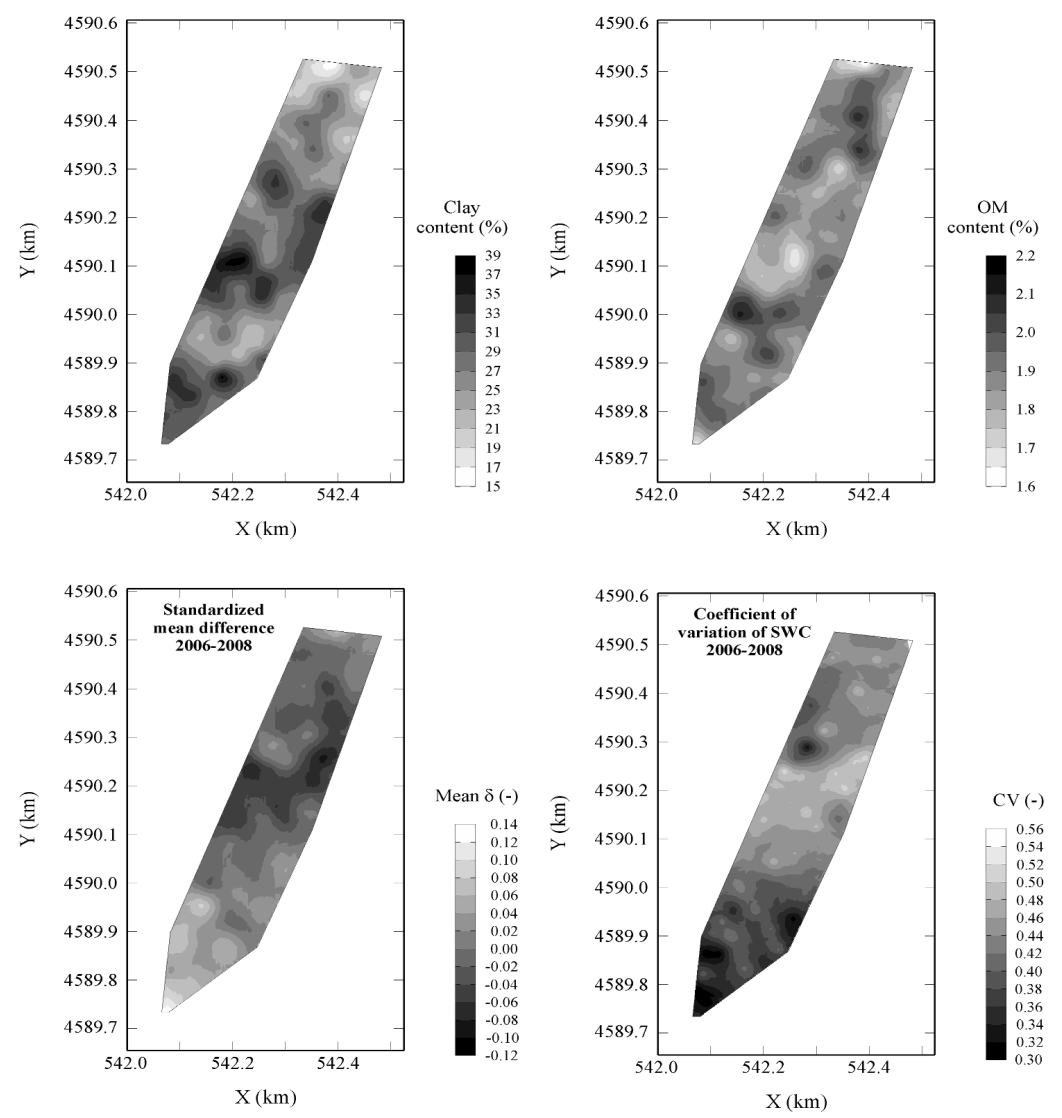

Figure 3. Maps of the clay, OM content, and the mean of the standardized relative differences produced using cokriging. The map of coefficient of variation of soil water content data is also reported.

Table 2. Decomposition of the components (regionalized factors). The eigenvalues and the percentage of variance accounted for at each spatial scale are also given.

\begin{tabular}{|c|c|c|c|c|c|c|c|c|c|c|c|c|c|}
\hline & Clay & $\mathrm{OM}$ & $\begin{array}{c}\delta_{i j} \\
170206\end{array}$ & $\begin{array}{c}\delta_{i j} \\
090506\end{array}$ & $\begin{array}{c}\delta_{i j} \\
300506\end{array}$ & $\begin{array}{c}\delta_{i j} \\
120207\end{array}$ & $\begin{array}{c}\delta_{i j} \\
060407\end{array}$ & $\begin{array}{c}\delta_{i j} \\
140507\end{array}$ & $\begin{array}{c}\delta_{i j} \\
100408\end{array}$ & $\begin{array}{c}\delta_{i j} \\
240408\end{array}$ & $\begin{array}{c}\delta_{i j} \\
090508\end{array}$ & $\begin{array}{l}\text { Eigen- } \\
\text { values }\end{array}$ & $\begin{array}{l}\text { Variance } \\
\text { Percentage }\end{array}$ \\
\hline \multicolumn{14}{|c|}{ a) Nugget effect } \\
\hline Factor 1 & 0.0182 & 0.4028 & -0.4163 & 0.1098 & 0.4948 & 0.5686 & 0.0151 & -0.0668 & -0.0716 & 0.0849 & -0.2589 & 1.3713 & 21.46 \\
\hline Factor 2 & -0.1206 & 0.0629 & 0.4428 & -0.0755 & 0.0398 & 0.3414 & 0.1356 & -0.3139 & 0.5679 & 0.4074 & 0.2370 & 1.0825 & 16.94 \\
\hline Factor 3 & 0.2636 & -0.4000 & 0.0947 & 0.3265 & 0.1919 & 0.3039 & -0.1154 & 0.6036 & 0.3220 & -0.1826 & 0.1050 & 0.9681 & 15.15 \\
\hline Factor 4 & -0.5003 & 0.2134 & -0.1706 & 0.3387 & -0.0443 & -0.2215 & -0.5816 & 0.1983 & 0.1712 & 0.3007 & 0.1101 & 0.8720 & 13.65 \\
\hline Factor 5 & 0.3655 & 0.1969 & 0.5236 & 0.2567 & -0.1795 & 0.0969 & -0.2345 & 0.0799 & -0.3736 & 0.3542 & -0.3459 & 0.6576 & 10.29 \\
\hline Factor 6 & 0.2801 & 0.1001 & -0.0213 & 0.6267 & 0.0309 & -0.2314 & -0.0331 & -0.5279 & 0.2568 & -0.3427 & -0.0229 & 0.5619 & 8.79 \\
\hline Factor 7 & -0.2863 & -0.0657 & 0.1247 & 0.1085 & 0.1804 & -0.3127 & 0.4108 & 0.1850 & 0.2680 & 0.0870 & -0.6882 & 0.4616 & 7.22 \\
\hline Factor 8 & 0.1407 & 0.4392 & -0.0928 & 0.2717 & -0.0995 & -0.1716 & 0.5771 & 0.3442 & -0.0603 & 0.1940 & 0.4155 & 0.3723 & 5.83 \\
\hline Factor 9 & -0.0715 & -0.5522 & -0.0703 & 0.2817 & 0.3922 & -0.1075 & 0.1333 & -0.2211 & -0.3762 & 0.4405 & 0.1951 & 0.0432 & 0.68 \\
\hline \multicolumn{14}{|c|}{ b) Spherical model (range $70 \mathrm{~m})$} \\
\hline Factor 1 & 0.3670 & -0.0615 & -0.2466 & -0.1938 & 0.4174 & -0.4179 & -0.1448 & 0.1103 & 0.2330 & 0.5358 & 0.1996 & 0.9182 & 29.86 \\
\hline Factor 2 & 0.1464 & 0.574 & 0.2795 & -0.0375 & 0.4704 & -0.1396 & -0.2009 & -0.1155 & -0.2403 & -0.4060 & 0.2292 & 0.8608 & 27.99 \\
\hline Factor 3 & 0.0838 & 0.3462 & 0.0259 & -0.6092 & -0.4577 & 0.0441 & -0.2513 & 0.1353 & 0.4395 & -0.1236 & 0.0043 & 0.6778 & 22.04 \\
\hline Factor 4 & 0.3588 & 0.2674 & -0.6364 & -0.0123 & -0.2018 & 0.0259 & 0.4870 & -0.1515 & -0.1916 & -0.1556 & 0.1791 & 0.3901 & 12.69 \\
\hline Factor 5 & -0.3146 & -0.249 & -0.2281 & -0.3096 & -0.0958 & 0.0882 & -0.4014 & -0.3694 & -0.3713 & 0.0619 & 0.4847 & 0.1863 & 6.06 \\
\hline Factor 6 & -0.4111 & -0.0495 & -0.4812 & -0.0836 & 0.2268 & -0.4051 & -0.1139 & -0.0543 & 0.1509 & -0.3960 & -0.4231 & 0.0421 & 1.37 \\
\hline \multicolumn{14}{|c|}{ b) Spherical model (range $500 \mathrm{~m})$} \\
\hline Factor 1 & 0.4246 & -0.2399 & 0.0755 & -0.0048 & -0.3850 & 0.1710 & -0.4424 & -0.3496 & 0.3258 & 0.2798 & -0.2768 & 1.5007 & 57.63 \\
\hline Factor 2 & -0.5609 & -0.0376 & -0.2505 & -0.4625 & -0.2929 & -0.1086 & 0.0044 & -0.1759 & 0.4281 & -0.2857 & -0.1176 & 0.6107 & 23.45 \\
\hline Factor 3 & 0.0313 & 0.2032 & -0.2167 & 0.4267 & -0.0901 & -0.1798 & -0.0838 & -0.3963 & 0.2551 & -0.0806 & 0.6728 & 0.4225 & 16.22 \\
\hline Factor 4 & 0.2916 & 0.1601 & -0.4922 & -0.2692 & -0.3558 & -0.1851 & 0.1089 & 0.4777 & 0.0217 & 0.3730 & 0.1846 & 0.0704 & 2.7 \\
\hline
\end{tabular}




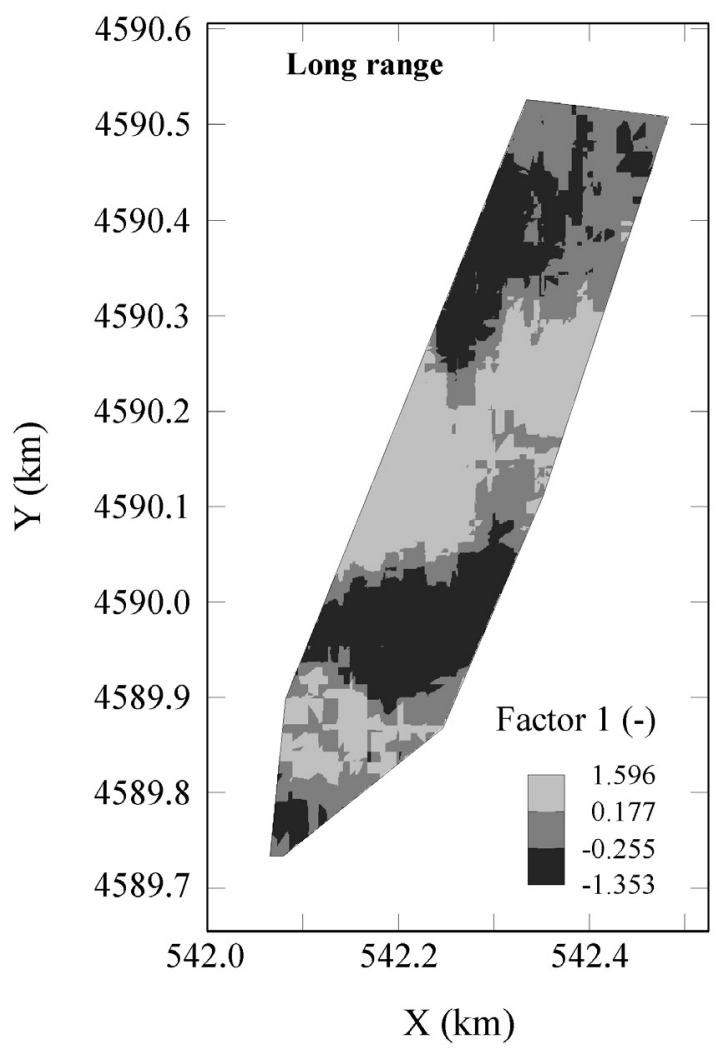

Figure 4. Map of the factor 1 at long range $(500 \mathrm{~m})$.

effect, because mostly affected by measurement error and variation at a scale smaller than $20 \mathrm{~m}$ (lag), only the first regionalized factor corresponding at long range $(500 \mathrm{~m})$ was considered for the final analysis, accounting for $58 \%$ of the variability at that spatial scale (Tab. 2). The first regionalized factor, as a new variable, will be the basis of the management zones delineation. From the Table 2, clay content has the higher principal component loading and that reflects the relative importance of clay content within the first regionalized factor.

Therefore, to classify this index into MZ, we preferred to utilise only the scores of the first factor at long range, because the one at short range produced a fine partitioning of the field into too small zones, which cannot actually be differentially managed by the farmer. The scores of the index at long range were split into three classes by using iso-frequency classes. The resultant map, depicting the MZ is shown in Figure 4 . The number of the created management zones was chosen so the MZ were practically "manageable" by farmer.

\section{Conclusions}

The proposed approach has then led to partition the field from the point of view of soil properties, into contiguous zones to be submitted to site-specific management. This study has indicated that different soil and multi-temporal properties can be used to delineate agricultural management zones by adopting a multivariate geostatistical approach. The method showed a great flexibility to combine data from several sources in the delineation of management zones.

However, as spatial and temporal variability in crop response depends on many factors, including weather, genetics, soil and landscape properties, management practices, stresses, pests and their dynamic interactions, it is better to use more variables of different type, combining both soil-landscape and crop information, to define more stable MZ. Using this delineation in the scope of site-site specific farm, would require additional experimental tests through crop measurements. Moreover, the static concept of MZ can be inadequate for variable application of crop inputs as water under variable meteorological conditions. In this case a better strategy might be to combine the use of $\mathrm{MZ}$ along with a remote infrared imaging of crop, so that crop water status can be instantaneously estimated and then irrigation can be more efficiently applied.

\section{Acknowledgments}

This research was funded by the Integrated system for development of southern cereal farming (SI.Cer.Me). Program for southern Italy development: Research and Technological Innovation. Resolution CIPE 17/2003 -1.1 and 83/2003.

\section{References}

Basso B., Ritchie J.T., Pierce F.J., Braga R.P., Jones J.W. 2001. Spatial validation of crop models for precision agriculture. Agr. Syst., 68:97-112.

Basso B., Bertocco M., Sartori L., Martin E.C. 2007. Analyzing the effects of climate variability on spatial of yield in a maize-wheat-soybean rotation. Eur. J. Agron., 26:82-91.

Bhatti A.U., Mulla D.J., Koehler F.E., Gurmani A.H. 1991. Identifying and removing spatial correlation from yield experiments. Soil Sci. Soc. Am. J., 55:15231528. 
Blackmore B.S. 2000. The interpretation of trends from multiple yield maps. Comput. Electron. Agr., 26:3751.

Boydell B., McBratney A.B. 2002, Identifying Potential within-Field Management Zones from Cotton-Yield Estimates. Precis. Agr., 3:9-23.

Carr P.M., Carlson G.R., Jacobsen J.S., Nielsen G.A., Skogley E.O. 1991. Farming soils, not fields: a strategy for increasing fertilizer profitability. J. Prod. Agr., 4:57-61.

Cassel D.K., Kachanoski R.G., Topp G.C. 1994. Practical considerations for using a TDR cable tester. Soil technology, 7:113-126.

Castrignanò A., Morari F., Morelli G.2006. Assessment of spatial relationship between some soil properties and electromagnetic induction scan, 1-6. In: Agricultural engineering for a better world. XVI CGR World Congress.

Castrignanò A., Buttafuoco G., Troccoli A., Colecchia S., Di Bitello V., Pisante M., Basso F., Cafiero G., Cammarano D., Basso B. 2008. Multivariate geostatistical analysis for delineation of management zones using crop index. Proceedings of EuroAgeng 2008 23th 25th June 2008, Hersonissos, Crete Isle, Greece. CD ROM (in print).

Castrignanò A., Giugliarini L., Risaliti R., Martinelli N. 2000. Study of spatial relationships among some soil physico-chemical properties of a field in central Italy using multivariate geostatistics, Geoderma, 97:39-60.

Comegna V., Basile A. 1994. Temporal stability of spatial patterns of soil water storage in a cultivated Vesuvian soil. Geoderma, 62:299-310.

Dalton F.N., van Genuchten M.Th. 1986. The time domain reflectometry method for measuring soil water content and salinity. Geoderma, 38:237-250.

Diker K., Heermann D.F., Brodahl M.K. 2004. Frequency analysis of yield for delineating yield response zones. Precis. Agr., 5:435-444.

Dobermann A., Ping J.L., Simbahan G.C., Adamchuk V.I. 2003. Processing of yield map data for delineating yield zones, 177-185. In: Stafford J.V., Werner A. (eds.): Proc. 4th European Conference on Precision Agriculture. Wageningen Academic Publishers, Wageningen, NL.

Doerge T.A. 1999. Management zone concepts [Online]. Available at http://www.ppi-far.org/ssmg (verified 14 June 2009).

Fleming K.L., Westfall D.G., Wiens D.W., Brodah M.C. 2000. Evaluating farmer developed management zone maps for variable rate fertilizer application. Precis. Agr., 2:201-215.

Fraisse C.W., Sudduth K.A., Kitchen N.R. 2001. Delineation of site-specific management zones by unsupervised classification of topographic attributes and soil electrical conductivity. Trans. ASAE, 44:155-166.

Fridgen J.J., Kitchen N.R., Sudduth K.A., Drummond S.T., Wiebold W.J., Fraisse C.W. 2004. Management
Zone Analyst (MZA): Software for Subfield Management Zone Delineation. Agronomy Journal, 96:100-108.

Geovariances, 2009. Isatis Technical References, version 9.0.0. Géovariances, Avon Cedex, France.

Goovaerts P., Chiang C.N. 1993. Temporal persistence of spatial patterns for mineralizable nitrogen and selected soil properties. Soil Sci. Soc. Am. J., 57:372-381.

Goovaerts P., Webster R. 1994. Scale-dependent correlation between topsoil copper and cobalt concentrations in Scotland. Eur. J. Soil Sci., 45:79-95.

Goovaerts P. 1992. Factorial kriging analysis: A useful tool for exploring the structure of multivariate spatial soil information. J. Soil Sci., 43:597-619.

Goovaerts P. 1997. Geostatistics for Natural Resources Evaluation. Oxford University Press, New York.

Goulard M., Voltz M. 1992. Linear coregionalization model: tools for estimation and choice of cross-variogram matrix. Math. Geol., 24:269-286.

Guber A.K., Gish T.J., Pachepsky Y.A., van Genuchten M.T., Daughtry C.S.T., Nicholson T.J., Cady R.E. 2008. Temporal stability in soil water content patterns across agricultural fields. Catena, 73, 1:125-133.

Jaynes D.B., Colvin T.S. 1997. Spatiotemporal variability of corn and soybean yield. Agron. J., 89:30-37.

Jaynes D.B., Hunsaker D.J. 1989. Spatial and temporal variability of water content and infiltration on a flood irrigated field. Trans. ASAE, 32, 4:1229-1238.

Johnson R.M., Richard E.P. 2003. Evaluation of crop and soil spatial variability in Louisiana sugarcane production systems. In: Robert P.C. et al. (eds.): Precision agriculture [CD-ROM]. Proc. Int. Conf., 6th, Minneapolis, MN. 14-17 July 2002. ASA, CSSA, and SSSA, Madison, WI.

Journel A.G., Huijbregts C.J. 1978. Mining geostatistics. Academic Press, San Diego, CA.

Kachanoski R.J., De Jong E. 1988. Scale dependence and the temporal persistence of spatial

Khosla R., Fleming K., Delgado J.A., Shaver T., Westfall D.G. 2002. Use of site-specific management zones to improve nitrogen management for precision agriculture. J. Soil Water Conserv., 57:513-518.

Khosla R., Shaver T. 2001. Zoning in on nitrogen needs. Colorado State University Agronomy Newsletter, 21:24-26.

Lamb J.A., Dowdy R.H., Anderson J.L., Rehm G.W. 1997. Spatial and temporal stability of corn grain yields. J. Prod. Agr., 10:410-414.

Lark R.M. 1998. Forming spatially coherent regions by classification of multivariate data: An example from the analysis of maps of crop yield. Int. J. Geogr. Inform. Sc., 12:83-98.

Matheron G. 1970. La théorie des variables régionalisées et ses applications. Les cahiers du centre de morphologie mathématique, fasc. 5 . 
Matheron G. 1982. Pour une analyse krigeante des données régionalisées. Rapport N-732, Centro de Géostatistiques, École des Mines de Paris, Fontainebleau, $22 \mathrm{pp}$.

McCann B.L., Pennock D.J., van Kessel C., Walley F.L. 1996. The development of management units for site specific farming, 295-302. In: Robert P.C., Rust R.H., Larson W.E. (eds.): Precision agriculture. Proc. Int. Conf., 3rd, Minneapolis, MN. 23-26 June 1996. ASA, CSSA, and SSSA, Madison, WI.

Moulin A.P., Beckie H.J., Pennock D.J. 1998. Strategies for variable rate nitrogen fertilization in hummocky terrain, 839-846. In: Robert P.C., Rust R.H., Larson W.E. (eds.): Precision Agriculture. Proceedings of the Fourth International Conference, ASA/CSSA/SSSA, Madison, WI, USA.

Mulla D.J. 1991. Using geostatistics and GIS to manage spatial patterns in soil fertility. In: Kranzler G. (ed.) Automated Agriculture for the 21st Century, 336-345. ASAE, St. Joseph, MI.

Mzuku M., Khosla R., Reich R., Inman D., Smith F., MacDonald L. 2005. Spatial Variability of Measured Soil Properties across Site-Specific Management Zones. Soil Sci. Soc. Am. J., 69:1572-1579.

Nolan S.C., Goddard T.W., Lohstraeter G. 2000. Assessing management units on rolling topography. In: Robert P.C. et al. (eds.): Precision agriculture. Proc. Int. Conf., 5th, Bloomington, MN. 16-19 July 2000. ASA, CSSA, and SSSA, Madison, WI.

Pagliai M. (ed.) 1997. Metodi di Analisi Fisica del Suolo (Physical Methods of Soil Analysis). Italian Ministry of Agriculture, Franco Angeli, Milan (in Italian), Italy.

Pires da Silva A., Nadler A., Kay B.D. 2001. Factors contributing to temporal stability in spatial patterns of water content in the tillage zone. Soil Tillage Res., 58:207-218.

Robinson D.A., Cooper J.D., Gardner C.M.K. 2002. Modelling the relative permittivity of soils using soil hygroscopic water content. J. Hydrol., 25:39-49.

Schepers A.R., Shanahan J.F., Liebig M.A., Schepers J.S., Johnson S.H., Luchiari A.Jr. 2004. Appropriateness of Management Zones for Characterizing Spatial Variability of Soil Properties and Irrigated Corn Yields across Years. Agron. J., 96:195-203.
Soil Survey Staff, 1999. Soil Taxonomy. Agriculture Handbook 436. USDA.-NRCS. Washington D.C.

Starr G.C. 2005. Assessing temporal stability and spatial variability of soil water patterns with implications for precision water management. Agricultural Water Management, 72:223-243.

Tallon L.K., Si B.C. 2003. Representative soil water benchmarking for environmental monitoring. Environ. Inform. Arch., 1:581-590.

Tomer M.D., Anderson J.L. 1995. Variation of soil water storage across a sand plain hill slope. Soil Sci. Soc. Am. J., 59:1091-1100.

Topp G.C., Davis J.L. 1985. Measurement of soil water content using time-domain reflectometry (TDR): a field evaluation. Soil Science Society of America Journal, 49:19-24.

Topp G.C., Davis J.L., Annan A.P. 1980. Electromagnetic determination of soil water content: Measurements in coaxial transmission lines. Water Resources Research, 16:574-582.

Vachaud G. et al. 1985. Temporal stability of spatially measured soil water probability density function, Soil Sci. Soc. Am. J., 49:822-828.

Violante P. (ed.) 2000. Metodi di Analisi Chimica del Suolo (Chemical Methods of Soil Analysis). Italian Ministry of Agriculture. Franco Angeli, Milan (in Italian), Italy.

Wackernagel H. 2003. Multivariate Geostatistics: an introduction with Applications. Springer-Verlag, Berlin, Germany.

Webster R., Oliver M.A. 2007. Geostatistics for Environmental Scientists. Wiley, Chichester, England.

Zadoks J.C. 1974. A decimal code for the growing stages of cereals. Weed Res., 14:415-421.

Zegelin S.J., White I., Russell G.F. 1992. A critique of the time domain reflectometry technique for determining field soil-water content. In: Advances in Measurement of Soil Physical Properties: Bringing Theory into Practice, 187-208. Soil Science Society of America, Madison, Wisconsin.

Zhai R., Kachanoski R.G., Voroney R.P. 1990. Tillage effects on the spatial and temporal variations of soil water. Soil Sci. Soc. Am. J., 54:186-192. 